\title{
PERFORMANCE BASED DYNAMIC ANALYSIS OF BASALT FIBER REINFORCED OVER CONVENTIONAL CONCRETE WITH LINEAR RESPONSE SPECTRUM
}

\author{
ANALYSIS
ARAVIND MURALI, YANAPU N V S B PRIYATHAM, KAVIARASU VIMALANATHAN \& SUNDARASETTY VAMSI SANKAR

Undergraduate Engineer, Department of Civil Engineering, SRM Institute of Science and Technology, SRM Nagar,

Kattankulathur, Tamil Nadu, India.

\begin{abstract}
Stability of the structure greatly depends on various factors including type of loading approaching it and the materials used for construction. The response of a structure constructed in areas of high seismic activity will be utterly different from the same structure constructed in a seismically stable area. The resulting devastation of the structure is mainly due to increase in the deflection of the structure due to lateral effect which will in-turn loose the internal resistance offered by every structural element. In this study, the efficiency of basalt fibre reinforced concrete in resisting heavy dynamic loadings is compared with the performance of conventional concrete structure by performing SRSS response spectrum analysis using STAAD.Pro software. The parameters such as mass participation factor, base shear, peak storey shear, storey and nodal displacement were obtained as a result of response spectrum analysis and are compared between the conventional and basalt fibre reinforced RCC structure. An improved trend was observed in the case of BFRC structure by providing internal resistance to various structural and dynamical parameters. Further, this study may be useful in incorporating the basalt fibres in real life construction due to their versatility in yielding under the combined effects of vertical and heavy seismic loading.
\end{abstract}

KEYWORDS: SRSS Response Spectrum analysis; Basalt Fibber Reinforcement; Seismic Analysis; STAAD.Pro; ElCentro acceleration-time series

Received: Oct 07, 2020; Accepted: Oct 27, 2020; Published: Nov 28, 2020; Paper Id.: IJCSEIERDOCT20201

\section{INTRODUCTION}

Structural design and analysis are a robust topic which greatly differs based on different factors such as materials used, types of loading, usage of the structure, environmental impact etc. Determining the impact load resistance and cement strength properties at initial level prior to their use in the construction is a predominant factor to be considered in construction of large structures. This is a very essential factor as the rate of the explosions due to industrial failures, earthquakes and terrorist attacks are occurring frequently around the world which results in intense damages to the structures due to dynamic impact. Hence, it becomes necessary to examine these factors and analyse before going to design large structures under seismically unstable zones.

In large structures like industrial buildings, long bridges, hydro and nuclear power plants, the safety and stability can be incorporated by understanding, analysing and representing the effects of these seismic and impact loads on the structures. Establishment of strong motion instrument arrays has become an important factor in incorporating earthquake loads on the large structures ${ }^{1}$. Before analysing and designing an earthquake resistant structure, it 
is very familiar to assume that the complete base of the structure is subjected to uniform ground motion. So, it can be said that the seismic load and motion is assumed to be taken equally and simultaneously by all the points attached to the structure. This speculation is very favourable, as it promotes and eases the dynamic analysis, which can be analysed and performed using the best suitable method called Response spectrum Analysis method. There exist many methods of response spectrum analysis which varies based on the different input parameters. Eugene Victor A. et Al. (2018) has compared two methods of Response spectrum analysis (RSA), which was a comparative analysis between Absolute and SRSS methods of Response spectrum with the help of STAAD.Pro software and concluded with SRSS method to be effective in predicting the response history of complex problems ${ }^{2}$. The usage of modified design response spectrum in model analysis values the analysis with more accurate results ${ }^{3}$. There are many comparative studies to prove the efficiency of RSA when compared to seismic coefficient method, which concludes that, the response spectrum analysis to predict exact values since it uses seismic load as an input.

The present study focuses on Response spectrum dynamic analysis of high-rise buildings based on general criteria that considers frequency domain analysis and substructure methods as its root basis. This has been incorporated for evaluating the complex response history of an eleven storey building, which is subjected to El-Centro seismic ground motion, including other loads and forces acting on the building. Considering all the analytical approaches, the SRSS response spectrum method was adopted in this study to exactly predict the dynamic response of the BFRC concrete structure over conventional RCC structure ${ }^{4}$. The usage of basalt fibres as a reinforcing material increases the stability of the structure and makes it resistant against seismic loads ${ }^{5,6}$. Corresponding to the material properties and the structural integrity of the composite members, the loads and their effects on each structural member differs accordingly. Many studies have already evaluated the effect of impact and seismic loading on the modified concrete materials, in which concrete has been altered with secondary materials ${ }^{7}$. However, in this study basalt fibre is considered for analysis to make it an alternative for reinforced concrete in construction of large structures. The addition of basalt fibres will directly hike the flexural strength of any structure, prevent the crack formation and higher deflections due to lateral loads could be controlled ${ }^{8}$. Also, the compressive strength of the BFRC has a higher rate compared with Conventional Reinforced Concrete when the fibre content present in the concrete is higher ${ }^{9} 10$. This study briefly compares the seismic efficiency of basalt fibre reinforced concrete structure over conventional RCC structure based on the response spectra obtained using STAAD Pro SRSS response spectrum method. Outcomes such as deflection, shear force, bending moments, mass participation factor, storey and nodal deflections, the efficiency of BFRC is verified.

\section{MATERIALS AND METHODOLOGY}

\subsection{Material specification}

Specific parameters have been considered based on the materials under consideration, structural orientation and loading conditions. This study incorporates basalt fibres into the conventional concrete mixture to find its efficiency in resisting the combined effects of lateral and dynamic loading with a view to obtain a quality outcome. The properties of conventional RCC and the Basalt fibre reinforced concrete given as an input in STAAD.Pro are given in Table 1.

Table 1: Concrete properties

\begin{tabular}{|l|c|c|c|}
\hline \multirow{2}{*}{ Material properties } & \multicolumn{2}{c|}{ Value } & \multirow{2}{*}{ Units } \\
\cline { 2 - 3 } & RCC & BFRC & \\
\hline Young's Modulus (E) & $2.236 \times 10^{7}$ & $2.977 \times 10^{7}$ & $\mathrm{kN} / \mathrm{m}^{2}$ \\
\hline Density (k) & 23.5616 & 23.5616 & $\mathrm{kN} / \mathrm{m}^{3}$ \\
\hline
\end{tabular}




\begin{tabular}{|l|c|c|c|}
\hline Poisson's Ratio $\left(\mathrm{n}_{\mathrm{u}}\right)$ & 0.2 & 0.2 & \\
\hline Thermal coefficient $(\alpha)$ & $1 \mathrm{e}-05$ & $1 \mathrm{e}-05$ & Per $^{\circ} \mathrm{F}$ \\
\hline Critical Damping & 0.05 & 0.05 & \\
\hline Shear Modulus $(\mathrm{G})$ & $9.316 \times 10^{6}$ & $1.24 \times 10^{7}$ & $\mathrm{kN} / \mathrm{m}^{2}$ \\
\hline Compressive Strength $\left(\mathrm{F}_{\mathrm{cu}}\right)$ & 20000 & $40120[7]$ & $\mathrm{kN} / \mathrm{m}^{2}$ \\
\hline
\end{tabular}

\subsection{Seismic Analysis Input parameters}

This study incorporates the following seismic definitions as listed in Table 2. The response spectrum analysis is carried out with a maximum modal mass of 20 numbers with El-Centro acceleration as its input seismic loading. The selection of the acceleration loading for this analysis was based on the worst peak ground acceleration, which had caused severe devastations to the high raised buildings. Other parameters such as zone, response reduction factor, Importance factor, geotechnical factors, damping ratios etc. were chosen based on the standard definitions prescribed in IS 1893 (Part 1):2002 $2^{11}$.

Table 2: Seismic definition parameters

\begin{tabular}{|l|c|c|}
\hline \multicolumn{1}{|c|}{ Parameters } & Value & Units \\
\hline Zone & 0.36 & - \\
\hline Response reduction Factor (R) & 5 & - \\
\hline Importance Factor (I) & 1.5 & - \\
\hline Rock and soil site factor (SS) & 2 & - \\
\hline Type of structure (ST) & 1 & - \\
\hline Damping ratio (DM) & 0.05 & seconds \\
\hline Period in X Direction (PX) & 0.445477 & seconds \\
\hline Period in Z Direction (PZ) & 0.469574 & \\
\hline
\end{tabular}

\subsection{Modal Parameters}

The SRSS method of response spectrum method is utilized to analyse the dynamic stability of the structure. The spectral series which was given as an input was the El-Centro acceleration data. This data is selected and has a damping ratio of 0.05 . The software STAAD.Pro analyses the structure based on an iterative method to predict the exact dynamic response of the structure, which requires appropriate case - specific parameters, which are listed in Table 3 and the basalt fibre properties are enlisted in Table $4^{12}$.

Table 3: Model parameters

\begin{tabular}{|c|c|c|}
\hline Description & Parameter/Method & Values \\
\hline Code & IS $1893-2002$ & - \\
\hline Combination Method & SRSS & - \\
\hline Type of Soil & Medium Soil & - \\
\hline Spectrum Type & El-Centro Acceleration data & - \\
\hline
\end{tabular}




\begin{tabular}{|c|c|c|}
\hline Damping Ratio & - & 0.05 \\
\hline \multirow{3}{*}{ Direction - RSX } & $\mathrm{X}$ & 0.036 \\
\cline { 2 - 3 } & $\mathrm{Y}$ & 0 \\
\cline { 2 - 3 } & $\mathrm{Z}$ & 0 \\
\hline \multirow{3}{*}{ Direction - RSY } & $\mathrm{X}$ & 0 \\
\cline { 2 - 3 } & $\mathrm{Y}$ & 0.036 \\
\hline \multirow{3}{*}{ Direction - RSZ } & $\mathrm{Z}$ & 0 \\
\cline { 2 - 3 } & $\mathrm{X}$ & 0 \\
\cline { 2 - 3 } & $\mathrm{Y}$ & 0.036 \\
\hline
\end{tabular}

Table 4: Basalt fibre parameters

\begin{tabular}{|c|c|c|c|c|c|c|}
\hline Type & $\begin{array}{c}\text { Diameter } \\
\left(\times 10^{-6} \mathrm{~mm}\right)\end{array}$ & $\begin{array}{l}\text { Length } \\
(\mathrm{mm})\end{array}$ & $\begin{array}{l}\text { Density } \\
\left(\mathrm{kN} / \mathbf{m}^{3}\right)\end{array}$ & $\begin{array}{c}\text { Tensile } \\
\text { Strength } \\
\left(\times 10^{3}\right. \\
\left.\mathrm{kN} / \mathbf{m}^{2}\right)\end{array}$ & $\begin{array}{c}\text { Elasticity } \\
\text { Modulus } \\
\left(\times 10^{3}\right. \\
\left.\mathrm{kN} / \mathbf{m}^{2}\right)\end{array}$ & $\begin{array}{c}\text { Elongation at } \\
\text { Break }(\%)\end{array}$ \\
\hline Value & 15 & 12 & 2.65 & $3500-4500$ & $95-115$ & -3.0 \\
\hline
\end{tabular}

The structural elements are modelled as beam elements in STAAD.Pro, whose dimensions are listed in Table 4. The tri-axial reduction factors that are used for designing the beam and column elements are given in Table 5. The reduction factors play a crucial role in delivering a dynamic response of the structure. Also, Figure 1 illustrates the 3-D view of the structural model after provision of the dimensions of the structural elements.

Table 4: Dimensions of structural element

\begin{tabular}{|c|c|}
\hline Elements & Length $(\mathbf{m})$ \\
\hline Columns & $0.35 \times 0.35$ \\
\hline Beams & $0.3 \times 0.3$ \\
\hline
\end{tabular}

Table 5: Reduction factors for beam

\begin{tabular}{|l|c|c|}
\hline \multicolumn{1}{c}{ Parameters } & \multicolumn{2}{c|}{ Value } \\
\cline { 2 - 3 } & Columns & Beams \\
\hline Reduction Factor for Cross-sectional Area (RAX) & 1 & 1 \\
\hline Reduction Factor for Torsion Constant (RIX) & 0.7 & 0.35 \\
\hline Reduction Factor for Moment of Inertia (RIY) & 0.7 & 0.35 \\
\hline Reduction Factor for Moment of Inertia (RIY) & 0.7 & 0.35 \\
\hline
\end{tabular}




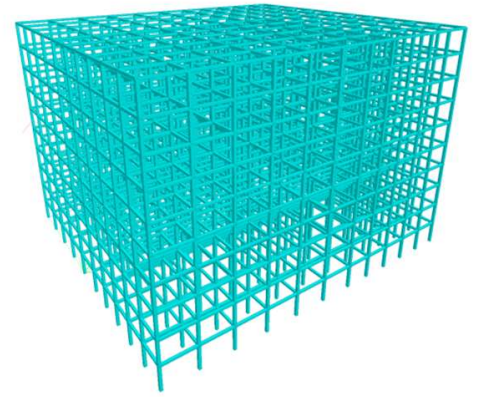

Figure 1: 3-Dimensional rendered view

\subsection{Analysis}

Response spectrum (RS) analysis is carried out in this project. This method is used for structural response to earthquakes and shocks which are non-deterministic, transient dynamic events. This method is based on a particular type of mode superposition. Response Spectrum is a function of frequency, showing the peak response of a harmonic oscillator which is assigned to a transient event. Step by step procedure in building analysis using STAAD.Pro is given below.

- Nodal points should be generated. Node points in the STAAD file were entered based on column positioning.

- Rendering of beams and columns. Beams and columns were drawn between corresponding node points, with the help of add beam command.

- 3- Dimensional view of the structure. Transitional repeat command was used in $\mathrm{X}, \mathrm{Y}$ and $\mathrm{Z}$ direction to plot the $3 \mathrm{D}$ view of the structure.

- Assigning properties and supports. Once the structure is created, the supports at the base of the structure are specified. Specific materials and cross-section of columns and beams were assigned

- 3- Dimensional rendering view. Once the property is assigned to the structural members, the 3-D rendering view can be seen.

- Assigning the specified seismic load. Before assigning the seismic load, the seismic load has to be defined with respect to the code IS $1893^{11}$ with floor weights. In $+X$ and $+Z$ directions, the loads have to be added with a selected seismic factor. $+\mathrm{Y}$ axis has to be considered if the structures fall under the conditions provided in the code IS 1893.

- Assigning wind loads. Before assigning the wind loads, the wind load has to be defined with respect to the code IS: 875 (Part 3) $-2002^{13}$ with exposure factor. In $+X,-X,+Z$, and $-Z$ directions, the loads have to be added with the load intensities along with the selected wind exposure factor. Figure 2 shows the wind load along $+X-$ axis acting on the structure.

- Assigning dead loads. Dead loads are evaluated and assigned for interior walls, external walls, parapet walls and the self-weight of the whole structure, corresponding to IS: 875 (Part 1) - 2002 ${ }^{14}$.

- Assigning live loads. A live load of $2 \mathrm{kN} / \mathrm{m}^{2}$ and $3 \mathrm{kN} / \mathrm{m}^{2}$ was assigned to rooms and the balconies respectively for each floor according to the code IS: 875 (Part 2) - 2002 ${ }^{15}$. Figure 3 shows the dead load and live load acting 
on the structure.

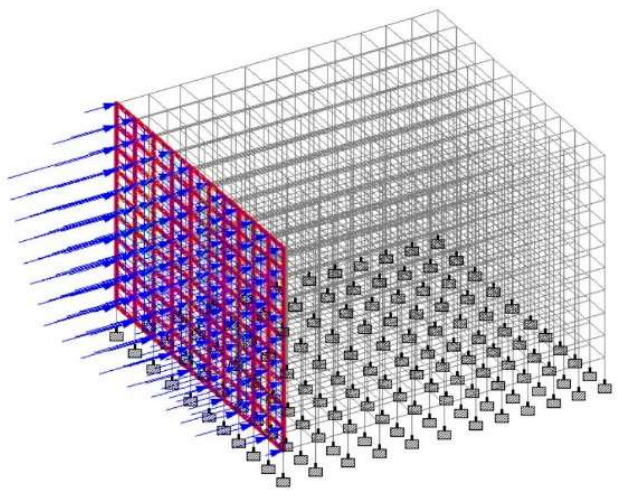

Figure 2; Wind Load along $+\mathrm{X}-$ axis

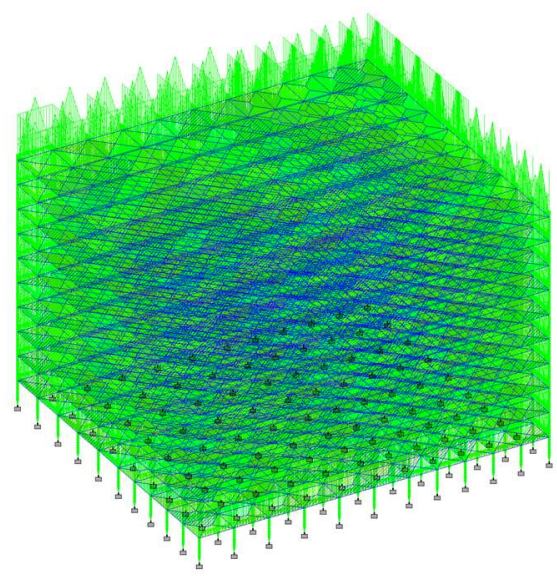

Figure 3. Dead and live load on structure

- $\quad$ Addition of load combinations. Once all the loads are assigned, a suitable factor of safety is given to all load combinations according to IS: 875 (Part 5) $-2002^{16}$ and IS 456:2000 ${ }^{17}$.

- $\quad$ Analysis of structure. Completing all the steps mentioned above, analysis was performed and errors and warnings were checked.

\subsection{Limitations}

The limitations of the analysis are listed below without which exact prediction of dynamic response of the structure is impossible.

- If the modal masses do not cross $75 \%$ in all of the first six modes, additional iterative modes must be added to obtain correct predictions. The number of modes is increased such that the cumulative sum of the modal mass participation factor must exceed $90 \%$. Additional modes will be evaluated till the reflection of warning in the output file stating "the spectral acceleration in the modes cannot be calculated."

- If the slab is to be designed as a one-way slab, then the floor loads for those kinds of slabs is to be provided unidirectional i.e., one-way distribution.

- The response quantities such as storey drift, storey displacement, torsion irregularities and the nodal displacements are purely dependent on the modal combinations for obtaining maximum magnitudes of the same.

- The SRSS method cannot process closely spaced modes which are based on the spectral acceleration calculation, which diverts the analysis to follow the CSM method.

\section{RESULTS AND DISCUSSIONS}

The applicability of basalt fibres used as a reinforcement to control heavy deflections and bending moments occurring in a structure when subjected to lateral loadings is analysed using SRSS (Square Root of Sum of Square) - response spectrum method (RSM) and compared with the conventional reinforced concrete structure. The SRSS method of response spectrum analysis being versatile in predicting the real behaviour of a structure accurately when subjected to dynamic effects was considered in this analysis. El-Centro earthquake loading was given as an input loading parameter in STAAD Pro, 
considering the worst peak ground acceleration ever since occurred. Along with the basic output parameters from the STAAD Pro software such as Bending Moments, Shear Force, Deflection and Axial Force, major outputs from RSM such as Mass Participation Factors, Base Shear, Peak Storey Shear, Nodal Displacement, Storey Displacement and Storey Drift were also obtained. These parameters were placed under comparison with the values obtained for a conventional RCC and BFRC structure and the outcomes of this analysis are discussed below in detail.

\subsection{Effect of Dynamic Loading on Structural Elements}

\subsubsection{Deflection}

The model had been analysed with both Conventional Concrete and Basalt Fibber Reinforced Concrete. It is found that the maximum deflection was occurring in element 533 (column) and 5 (beam) and its respective values in $\mathrm{mm}$ are given in Table 6. The deflection in cases of RCC columns and beams was $27.27 \mathrm{~mm}$ and $13.56 \mathrm{~mm}$ respectively which was gradually reduced to $20.49 \mathrm{~mm}$ and $10.18 \mathrm{~mm}$ in the case of BFRC columns and beams respectively. This clearly infers us with a reduction in the deflection of columns and beams of about $24.92 \%$ and $24.86 \%$ respectively after the addition of Basalt Fibber as the reinforcement to the Conventional Concrete. This may be due to the increase in the flexural strength provided by the basalt fibres used as the reinforcement. Figure 4 visualizes the deflection occurring in the structural elements for the loading condition RSX.

Table 6: Maximum deflections in the structural elements

\subsubsection{Bending Moment}

\begin{tabular}{|c|c|c|}
\hline Deflection (mm) & RCC & BFRC \\
\hline Columns & 13.56 & 10.18 \\
\hline Beams & 27.27 & 20.49 \\
\hline
\end{tabular}

The values for positive and negative bending moments are given in Table 7. It is found that both positive and negative Bending Moment along Z-Axis and Y-Axis has been reduced in the case of BFRC while compared with RCC. Hence it can be concluded that the interlinked fibres make the structure resistant against bending failures, thereby increasing its bending capacity. Figure 5 illustrates the bending moment in the structure elements for 1.5 (DL $+\mathrm{LL}$ ) load combination.
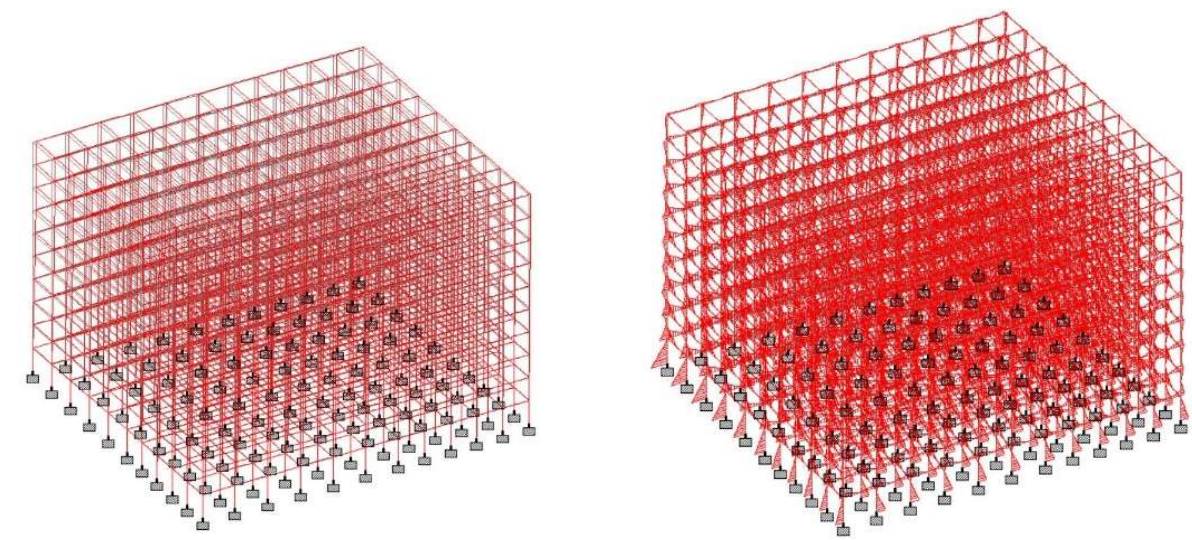

Figure 4: Deflection of the structure (RSX) Figure 5. Bending moment (1.5 (DL+LL) load) 
Table 7: Maximum bending moment in the structural elements

\begin{tabular}{|c|c|c|c|c|}
\hline $\begin{array}{c}\text { Structural } \\
\text { element }\end{array}$ & $\begin{array}{c}\text { Direction of bending } \\
\text { moment }\end{array}$ & Specification & $\begin{array}{c}\text { Maximum positive BM } \\
(\mathrm{kN}-\mathrm{m})\end{array}$ & $\begin{array}{c}\text { Maximum negative } \\
\text { BM (kN-m) }\end{array}$ \\
\hline \multirow{4}{*}{ Columns } & \multirow{2}{*}{$\mathrm{M}_{\mathrm{z}}$} & $\mathrm{RCC}$ & 13367.45 & 7097.66 \\
\hline & & BFRC & 13107.6188 & 6997.46 \\
\hline & \multirow{2}{*}{$\mathrm{M}_{\mathrm{y}}$} & $\mathrm{RCC}$ & 11490.64 & 15804.77 \\
\hline & & BFRC & 11100.81 & 15698.97 \\
\hline \multirow{4}{*}{ Beams } & \multirow{2}{*}{$\mathrm{M}_{\mathrm{z}}$} & $\mathrm{RCC}$ & 11048.43 & 10184.6 \\
\hline & & BFRC & 10739.72 & 9607.35 \\
\hline & \multirow{2}{*}{$\mathrm{M}_{\mathrm{y}}$} & $\mathrm{RCC}$ & 1040.89 & 688.72 \\
\hline & & BFRC & 866.12 & 606.23 \\
\hline
\end{tabular}

\subsubsection{Shear Force}

The values for positive shear force and negative shear force are listed in Table 8. From the comparative analysis, it was found that both positive and negative shear force along Z-Axis and Y-Axis has been reduced in the case of BFRC when placed under comparison with RCC. The combined effects of basalt fibre reinforcement along with the stirrups in the beams and columns help in the increase in the shear capacity of the structure. This behaviour of the structure in line with the experimental works of Mohsen A. Issa et.al $(2015)^{17}$. The shear force in the structure elements were of 1.2 (DL + LL+ELZ) load combination.

Table 8: Maximum shear force in the structural elements

\begin{tabular}{|c|c|c|c|c|}
\hline \multirow{2}{*}{$\begin{array}{c}\text { Structural } \\
\text { element }\end{array}$} & $\begin{array}{c}\text { Direction of } \\
\text { shear force }\end{array}$ & Specification & $\begin{array}{c}\text { Maximum + VE } \\
\mathbf{S F} \\
\mathbf{( k N )}\end{array}$ & $\begin{array}{c}\text { Maximum -VE } \\
\mathbf{S F} \\
\mathbf{( k N )}\end{array}$ \\
\hline \multirow{3}{*}{ Columns } & \multirow{2}{*}{$\mathrm{F}_{\mathrm{z}}$} & $\mathrm{RCC}$ & 172.481 & 11.818 \\
\cline { 3 - 5 } & \multirow{2}{*}{$\mathrm{F}_{\mathrm{y}}$} & $\mathrm{BFRC}$ & 170.427 & 11.13 \\
\cline { 3 - 5 } & \multirow{3}{*}{ Beams } & $\mathrm{RCC}$ & 114.377 & 142.989 \\
\cline { 3 - 5 } & \multirow{2}{*}{$\mathrm{F}_{\mathrm{z}}$} & $\mathrm{BFRC}$ & 112.813 & 138.177 \\
\cline { 2 - 5 } & \multirow{2}{*}{$\mathrm{F}_{\mathrm{y}}$} & $\mathrm{BFRC}$ & 154.18 & 8.161 \\
\cline { 3 - 5 } & & $\mathrm{RCC}$ & 152.156 & 7.85 \\
\hline
\end{tabular}

\subsubsection{Peak Storey Shear}

Based on the total lateral loads approaching the structure and seismic definitions, the peak storey shear is determined, which is the ultimate dynamic force distributed over every individual storey. This indirectly depicts the ultimate loadcarrying capacity of the structure, through which the efficiency of the material used for the construction could be derived. It can be visualized that, as the height of the structure is increasing, the peak storey shear is decreasing and the total load is distributed gradually along with the altitude of the structure. The peak storey shear of BFRC is higher when compared to 
the RCC structure, due to its higher load carrying capacity and initial compressive strength. Table 9 shows the values of peak storey shear of the complete structure.

Table 9: Peak storey shear

\begin{tabular}{|c|c|c|c|c|c|}
\hline \multirow{2}{*}{ Story } & \multirow{2}{*}{ Level (m) } & \multicolumn{4}{|c|}{ Peak Storey shear (kN) } \\
\cline { 3 - 6 } & & RCC & BFRC & RCC & BFRC \\
\cline { 3 - 6 } & & 450.28 & 519.56 & 436.85 & 504.06 \\
\hline $\mathbf{1 0}$ & 35 & 854.24 & 985.66 & 916.68 & 1057.71 \\
\hline $\mathbf{9}$ & 31.5 & 1096.41 & 1265.09 & 1286.47 & 1484.39 \\
\hline $\mathbf{8}$ & 28 & 1263.41 & 1457.78 & 1540.8 & 1777.84 \\
\hline $\mathbf{7}$ & 24.5 & 1428.91 & 1648.73 & 1717.24 & 1981.43 \\
\hline $\mathbf{6}$ & 21 & 1576.68 & 1819.24 & 1877.22 & 2166.01 \\
\hline $\mathbf{5}$ & 17.5 & 1697.04 & 1958.12 & 2060.16 & 2377.11 \\
\hline $\mathbf{4}$ & 14 & 1832.46 & 2114.37 & 2250.47 & 2569.69 \\
\hline $\mathbf{3}$ & 10.5 & 1975.18 & 2279.05 & 2395.45 & 2763.98 \\
\hline $\mathbf{2}$ & 7 & 2047.2 & 2362.14 & 2454.62 & 2832.24 \\
\hline $\mathbf{1}$ & 3.5 & 2047.2 & 2362.14 & 2454.62 & 2832.24 \\
\hline $\mathbf{B a s e}$ & 0 & & & & \\
\hline & & & & & \\
\hline
\end{tabular}

\subsubsection{Mass Participation Factors in Percentage}

The Mass participation factor (MPF) in percentage for each modal mass is graphically represented in the figure below. The structure is considered to be resistant against the approaching earthquake impact, when the modal mass factor is above $75 \%$ in higher mode. The first two MPFs are falling below $75 \%$ hence it was necessary to perform a dynamic analysis to discover the structures efficiency under severe seismic loadings. The analysis revealed an improvement in the MPF in the successive modal masses attaining the highest peak of $92.64 \%$ and $90.11 \%$ in the $\mathrm{X}$ and $\mathrm{Z}$ axis respectively at Mode 20 . Hence, it can be said that the efficiency of the structure under dynamic loading is validated. Figure 7 depicts the cumulative mass participation factor in percentage for $\mathrm{X}-$ axis and $\mathrm{Z}$ - axis. 


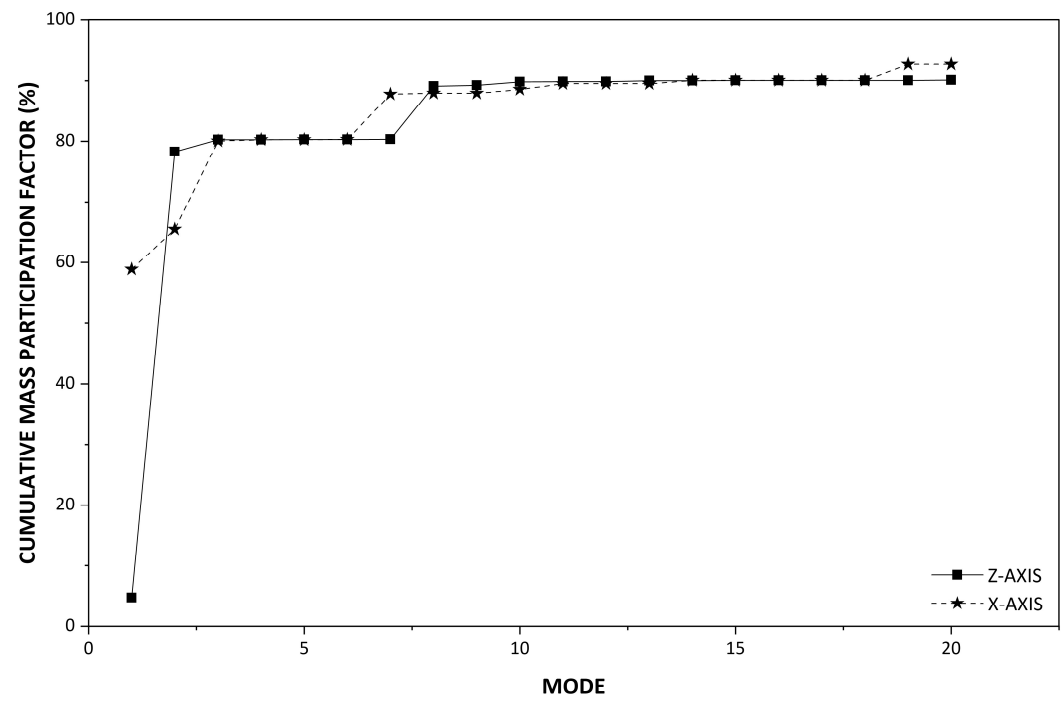

Figure 7: Cumulative mass participation factors for $\mathrm{X}-$ axis and $\mathrm{Z}-$ axis

\subsubsection{Base shear}

Base shear of BFRC structure is in increasing trend when compared to RCC structure which can be concluded from Table 10. This may be due to the higher compressive strength of BFRC as an input when compared to conventional RCC. Also, the base shear is calculated with the factor of total weight of the structure; as the unit weight of concrete varies for both the cases, the base shear also proportionally varies as given in Equation 1 and the pictorial representation was given in Figure 8.

$$
\mathbf{V}_{\mathbf{b}}=\mathbf{A}_{\mathbf{h}} \times \mathbf{W}
$$

Where,

$$
\mathrm{A}_{\mathrm{h}}=\frac{Z \times I \times \mathrm{Sa}}{2 \times R \times g}
$$

$=$ Design horizontal seismic coefficient

$\mathrm{V}_{\mathrm{b}}=$ Design seismic base shear

$\mathrm{W}=$ Seismic Weight of the building

$\mathrm{Z}=$ Zone factor, Table 2

$\mathrm{I}=$ Importance Factor, Table 6

$\mathrm{R}=$ Response Reduction Factor, Table 7

$\frac{\mathrm{Sa}}{g}=$ Average Response Acceleration Coefficient, Figure 2

Table 10: Base shear for $X-$ axis and $Z$ - axis

\begin{tabular}{|c|c|c|c|c|}
\hline \multirow{3}{*}{ Mode } & \multicolumn{4}{|c|}{ Base Shear (kN) } \\
\cline { 2 - 5 } & \multicolumn{3}{|c|}{ X - axis } & \multicolumn{2}{c|}{ Z-axis } \\
\cline { 2 - 5 } & RCC & BFRC & RCC & BFRC \\
\hline 1 & 1795.62 & 2071.87 & 144.71 & 166.97 \\
\hline 2 & 206.6 & 238.38 & 2299.42 & 2653.17 \\
\hline
\end{tabular}




\begin{tabular}{|c|c|c|c|c|}
\hline 3 & 492.41 & 568.16 & 67.2 & 77.54 \\
\hline 4 & 10.89 & 12.57 & 0.59 & 0.68 \\
\hline 5 & 0 & 0 & 1.48 & 1.71 \\
\hline 6 & 4.36 & 5.03 & 0.01 & 0.02 \\
\hline 7 & 694.1 & 800.88 & 5.39 & 6.22 \\
\hline 8 & 13.85 & 15.98 & 841.6 & 971.08 \\
\hline 9 & 0.11 & 0.12 & 13.49 & 15.57 \\
\hline 10 & 64.3 & 74.19 & 58.08 & 67.02 \\
\hline 11 & 105.12 & 121.29 & 1.95 & 2.24 \\
\hline 12 & 0.01 & 0.01 & 0 & 0 \\
\hline 13 & 0.05 & 0.05 & 21.51 & 24.81 \\
\hline 14 & 62.46 & 72.07 & 0.08 & 0.09 \\
\hline 15 & 0.01 & 0.01 & 0.67 & 0.78 \\
\hline 16 & 0.67 & 0.77 & 0 & 0 \\
\hline 17 & 0.19 & 0.22 & 0 & 0 \\
\hline 18 & 0.02 & 0.03 & 0.05 & 0.05 \\
\hline 19 & 424.74 & 490.08 & 0.13 & 0.15 \\
\hline 20 & 0.05 & 0.06 & 2.1 & 2.42 \\
\hline \multicolumn{5}{|c|}{ XXIS } \\
\hline
\end{tabular}
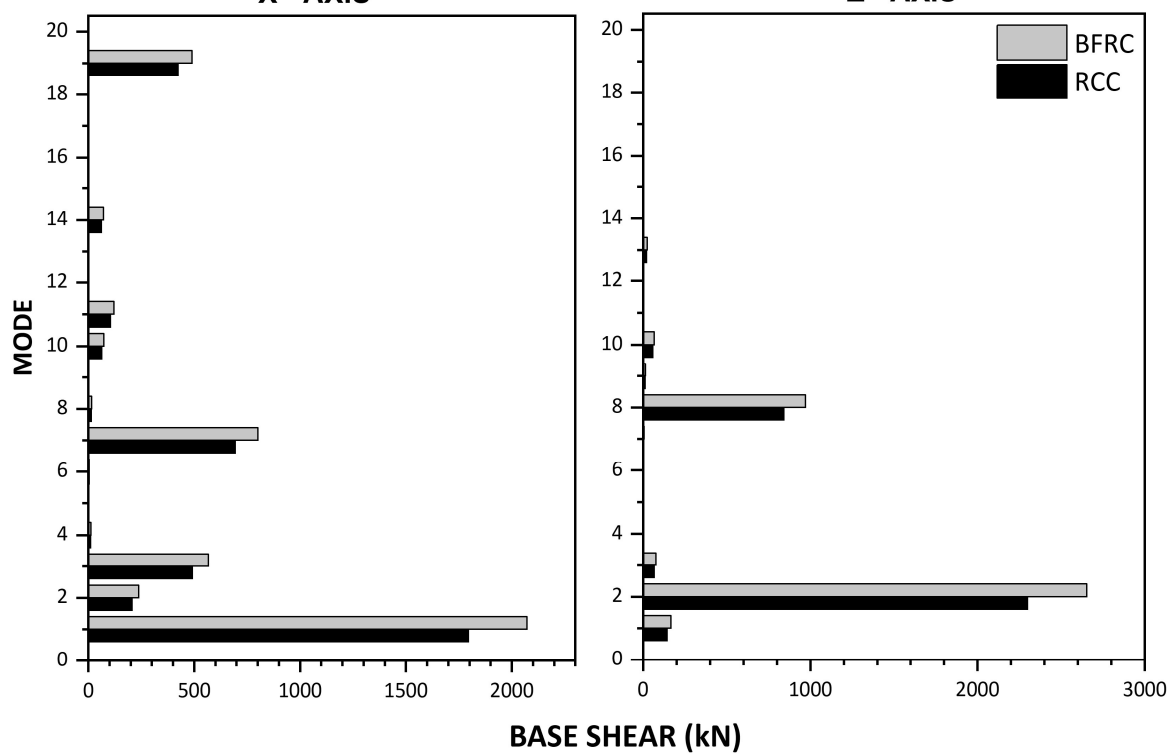

Figure 8: Base shear for $\mathrm{X}$ - axis and $\mathrm{Z}$ - axis

\subsubsection{Story Drift and Displacement}

The greatest story drift and its corresponding displacement were considered for the worst loading combination for the $\mathrm{X}-$ Axis and $\mathrm{Z}-$ Axis are listed in Table 11 and Table 12. As the height of the building increases, the story displacement also increases due to the seismic activity. Since there is an increase in the compressive and bending strength of the conventional concrete due to the addition of basalt fibres, the displacement in each storey decreases while compared with RCC structure. Whereas, storey drift is the relative difference between the consecutive stories, which proportionally decreases as the storey displacement is decreasing in both of the cases. 
Table 11: Storey drift and displacement for $\mathrm{X}$ - axis

\begin{tabular}{|c|c|c|c|c|c|c|c|c|}
\hline \multirow{3}{*}{ Story } & \multirow{3}{*}{ Height } & \multirow{2}{*}{\multicolumn{2}{|c|}{$\begin{array}{c}\text { Average displacement } \\
(\mathbf{m m})\end{array}$}} & \multirow{2}{*}{\multicolumn{2}{|c|}{$\begin{array}{c}\text { Drift (mm) } \\
\text { X - axis }\end{array}$}} & \multirow{2}{*}{\multicolumn{2}{|c|}{ Ratio }} & \multirow{3}{*}{ Status } \\
\hline & & & & & & & & \\
\hline & & RCC & BFRC & RCC & BFRC & RCC & BFRC & \\
\hline Base & 0 & 0 & 0 & 0 & 0 & L/999 & L/999 & PASS \\
\hline 1 & 3.5 & 30.54 & 22.939 & 30.54 & 22.939 & $\mathrm{~L} / 114$ & $\mathrm{~L} / 152$ & PASS \\
\hline 2 & 7 & 85.959 & 64.565 & 55.419 & 41.626 & $\mathrm{~L} / 63$ & $\mathrm{~L} / 84$ & PASS \\
\hline 3 & 10.5 & 146.766 & 110.238 & 60.807 & 45.673 & $\mathrm{~L} / 57$ & $\mathrm{~L} / 76$ & PASS \\
\hline 4 & 14 & 207.392 & 155.776 & 60.626 & 45.538 & $\mathrm{~L} / 58$ & $\mathrm{~L} / 58$ & PASS \\
\hline 5 & 17.5 & 265.448 & 199.382 & 58.055 & 43.606 & $\mathrm{~L} / 60$ & $\mathrm{~L} / 80$ & PASS \\
\hline 6 & 21 & 319.071 & 239.659 & 53.624 & 40.277 & $\mathrm{~L} / 65$ & $\mathrm{~L} / 87$ & PASS \\
\hline 7 & 24.5 & 366.296 & 275.131 & 47.225 & 35.471 & $\mathrm{~L} / 74$ & L /98 & PASS \\
\hline 8 & 28 & 404.965 & 304.175 & 38.669 & 29.045 & $\mathrm{~L} / 90$ & $\mathrm{~L} / 120$ & PASS \\
\hline 9 & 31.5 & 433.004 & 325.236 & 28.039 & 21.061 & $\mathrm{~L} / 125$ & $\mathrm{~L} / 166$ & PASS \\
\hline 10 & 35 & 449.72 & 337.792 & 16.716 & 12.556 & $\mathrm{~L} / 209$ & $\mathrm{~L} / 279$ & PASS \\
\hline
\end{tabular}

Table 12: Storey Drift and Displacement for $\mathrm{Z}$ - Axis

\begin{tabular}{|c|c|c|c|c|c|c|c|c|}
\hline \multirow{3}{*}{ Story } & \multirow{3}{*}{ Height } & \multirow{2}{*}{\multicolumn{2}{|c|}{$\begin{array}{c}\text { Average displacement } \\
(\mathbf{m m})\end{array}$}} & \multirow{2}{*}{\multicolumn{2}{|c|}{$\begin{array}{c}\text { Drift (mm) } \\
\text { Z - axis }\end{array}$}} & \multirow{2}{*}{\multicolumn{2}{|c|}{ Ratio }} & \multirow{3}{*}{ Status } \\
\hline & & & & & & & & \\
\hline & & RCC & BFRC & RCC & BFRC & RCC & BFRC & \\
\hline Base & 0 & 0 & 0 & 0 & 0 & L/999 & L/999 & PASS \\
\hline 1 & 3.5 & -68.276 & -51.283 & 68.276 & 5.1283 & $\mathrm{~L} / 51$ & L/68 & PASS \\
\hline 2 & 7 & -189.45 & -142.301 & 121.177 & 91.018 & $\mathrm{~L} / 29$ & $\mathrm{~L} / 38$ & PASS \\
\hline 3 & 10.5 & -317.51 & -238.487 & 128.058 & 96.186 & $\mathrm{~L} / 27$ & $\mathrm{~L} / 36$ & PASS \\
\hline 4 & 14 & -439.7 & -330.267 & 122.192 & 91.78 & $\mathrm{~L} / 28$ & $\mathrm{~L} / 38$ & PASS \\
\hline 5 & 17.5 & -551.42 & -414.182 & 111.72 & 83.915 & $\mathrm{~L} / 31$ & $\mathrm{~L} / 42$ & PASS \\
\hline 6 & 21 & -649.9 & -488.146 & 98.472 & 73.964 & $\mathrm{~L} / 35$ & $\mathrm{~L} / 47$ & PASS \\
\hline 7 & 24.5 & -732.65 & -550.307 & 82.757 & 62.16 & $\mathrm{~L} / 42$ & $\mathrm{~L} / 56$ & PASS \\
\hline 8 & 28 & -797.26 & -598.832 & 64.605 & 48.526 & $\mathrm{~L} / 54$ & $\mathrm{~L} / 72$ & PASS \\
\hline 9 & 31.5 & -841.73 & -632.233 & 44.467 & 33.401 & $\mathrm{~L} / 79$ & $\mathrm{~L} / 105$ & PASS \\
\hline 10 & 35 & -866.75 & -651.029 & 25.024 & 18.796 & $\mathrm{~L} / 140$ & $\mathrm{~L} / 186$ & PASS \\
\hline
\end{tabular}

\subsubsection{Nodal Displacement vs. Storey Graphs}

The nodal displacement acts as a governing parameter in proving the efficiency of basalt fibre as fibre reinforcement in the conventional concrete. From Figure 9 and Figure 10, it can be clearly seen that the nodes at higher altitudes experience higher displacement due to the effect of dynamicity, which gradually decreases as the nodal height decreases. This smooth pattern was the same as that obtained in many similar studies. The nodal points are at $\mathrm{x}=0 \mathrm{~m}, \mathrm{y}=3.5-35 \mathrm{~m}$ and $\mathrm{z}=45 \mathrm{~m}$. The displacements are drastically decreased in the case of BFRC structure when compared to conventional RCC structure proving its efficiency to withstand heavy bending in all the axis planes. 


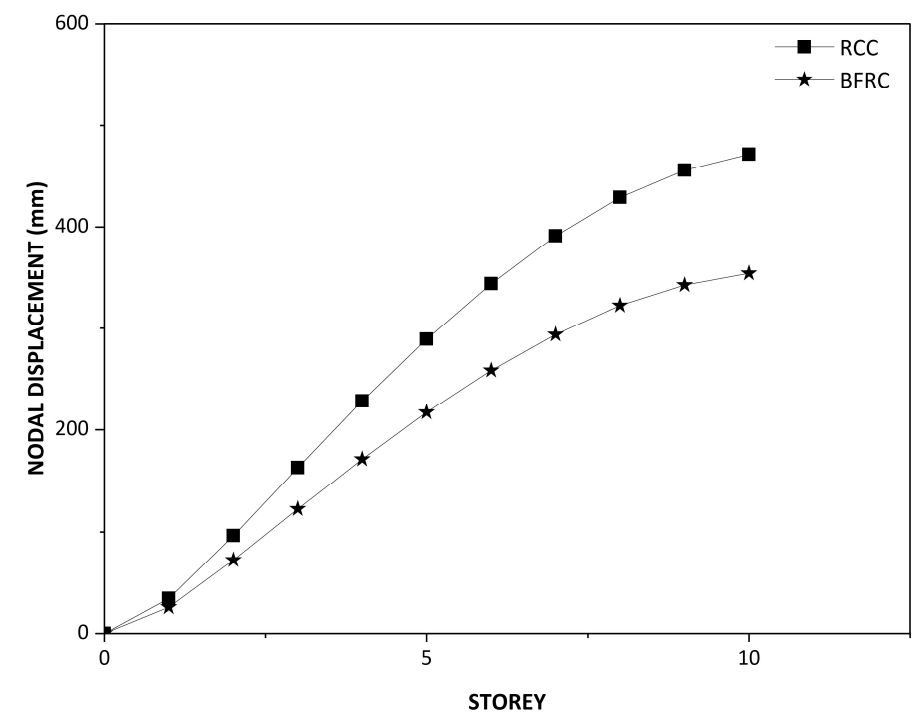

Figure 9: Nodal displacement vs. storey for $X$ - axis

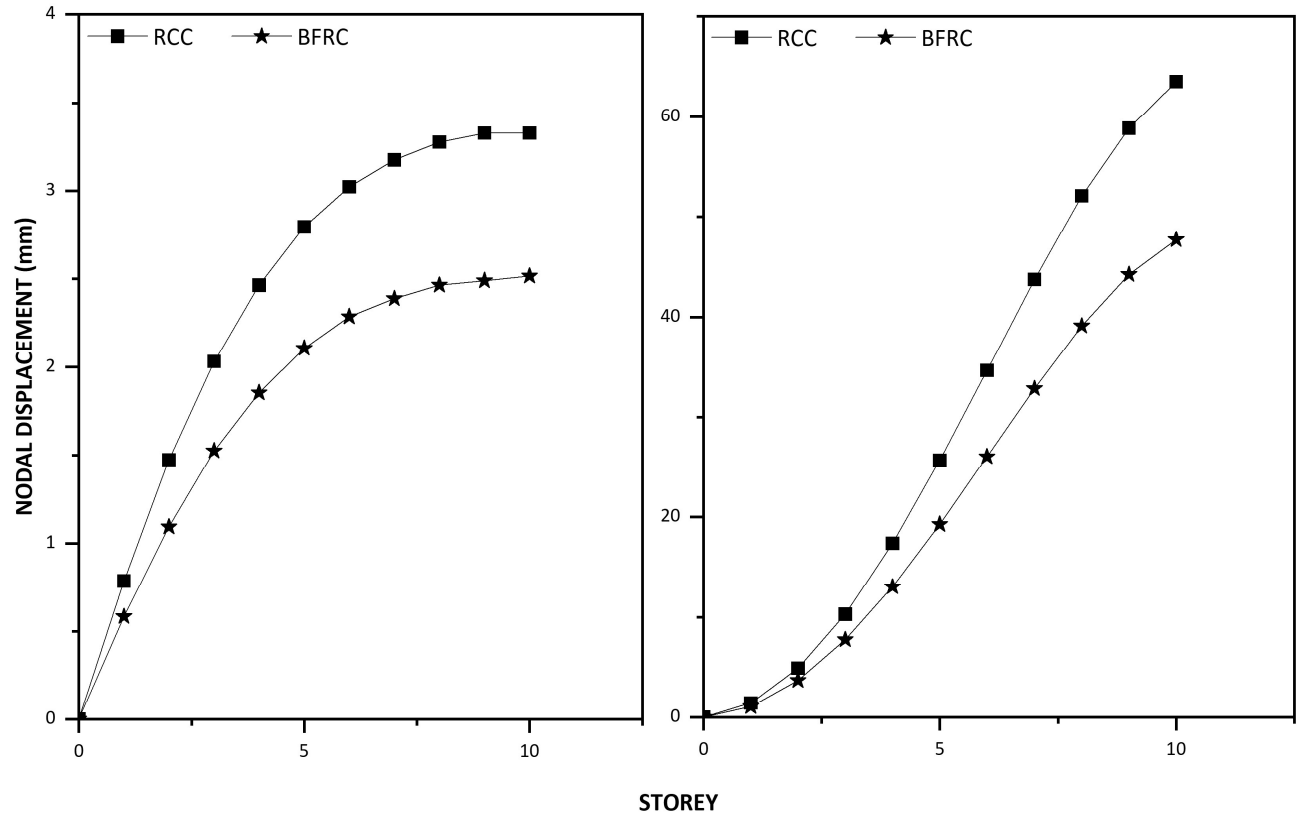

Figure 10: Nodal displacement vs. storey for $Y-$ axis and $Z-$ axis

\section{Concluding Remarks}

The response spectrum dynamic analysis has been performed in the STAAD.Pro Interface to assess the applicability and efficiency of structure constructed with basalt fibre reinforced concrete over the conventional RCC structure. The SRSS method of response spectrum being versatile in predicting exactly the dynamic response of a structure has been incorporated in this study. There was a drastic reduction in the deflection, storey and nodal displacement of the BFRC structure in all the three directions when compared to the conventional RC structure. The reason behind this suppression may be due to the higher compressive strength and increased load carrying capacity of the structure composed of BFRC elements. This indirectly proves the increase in the flexural capacity of the BFRC elements thereby yielding higher capacity before the failure occurs when compared with RCC elements. From the dynamic analysis, it was revealed that, the BFRC structure is seismically more stable than the conventional RCC structure, reaching a mass participation factor of 
90.11. Also, the peak storey shear and the base shear of the BFRC structure surpassed the conventional RCC structure proving it efficiency to withstand higher multiples of load combination. This study will be very useful for carrying out experimental dynamic analysis by incorporating basalt fibre as a reinforcing material due to its acceptable analytical and computational results.

\section{ACKNOWLEDGEMENT}

The authors would like to acknowledge faculties of Department of Civil Engineering, SRM Institute of science, especially Ms. T. M. Jeyashree and Mr. Manikandaprabhu @ Saravanan, Assistant professors, who had given constant motivation and insightful support throughout this research work.

\section{REFERENCES}

1. Alok Goyal and Anil K. Chopra (1989) Earthquake Response Spectrum Analysis of Intake-Outlet Towers. Journal of Engineering Mechanics 115: 1413-1433.

2. A. Eugene Victor, S. Yokesh and K. Preethi (2018) A Comparative Analysis on Absolute and SRSS Methods of Response Spectrum using STAAD-PRO. International Journal of Engineering Research \& Technology 7(12): 214-217.

3. Pattamon Sangin \& Sirilak Khotsuwan, "Development of Novel EST-SSR Markers to Assess Genetic Diversity in Curcuma Longa L.", International Journal of Bio-Technology and Research (IJBTR), Vol. 9, no. 2, pp. 1-8

4. S.S. Patil, S.A. Ghadge, C.G. Konapure et al. (2013) Seismic Analysis of High-Rise Building by Response Spectrum Method. International Journal of Computational Engineering Research 3(3): 272-279.

5. Zhang Huang, Wang Bin, Xie Aoyu et al. (2017) Experimental study on dynamic mechanical properties and constitutive model of basalt fibre reinforced concrete. Construction and Building Materials 152:154-167.

6. Ayman Y. Amin \& Ayman A. Diab , "QTL Mapping of Wheat (Triticum aestivum L.) in Response to Salt Stress ", International Journal of Bio-Technology and Research (IJBTR), Vol. 3, No 4, pp. 47-60

7. Wilson Nguyen, William Trono, Marios Panagiotou et al. (2014) Seismic Response of a Hybrid Fiber-Reinforced Concrete Bridge Column Detailed for Accelerated Bridge Construction. Pacific Earthquake Engineering Research Center Technical Report Number: PEER 2014/19.

8. Khan, Mehran, Mingli Cao et al. Experimental and Empirical Study of Basalt Fibber Reinforced Concrete. Building Tomorrow's Society, Paper ID - MA39_0610035833.

9. Sateshkumar, Paul Oluwaseun Awoyer, Tamilarasan Kandasamy et al. Impact resistance of high strength chopped basalt fibre-reinforced concrete.

10. S. Cynthia, A. Victor Anthony Raj, P. Sagayaraj \& B. Milton Boaz, "Growth, Morphological, Optical and Physical Property Studies on Nonlinear Optical Single Crystals of MMTD “, International Journal of Applied Mathematics \& Statistical Sciences (IJAMSS), Vol. 3, No 3, pp. 53-62

11. Redha I.Al-Bayati, Olfat A. Nief \& Ahmad N.Hameed, "Synthesis of 2, 5- disubstituted-1, 3, 4-thiadiazole Derivatives and Evaluation of Their Antibacterial Activity ", International Journal of Applied and Natural Sciences (IJANS), Vol. 4, Issue 2, pp. 1-8

12. Dehong Wang, Yanzhong Ju, Hao Shen et al. (2019) Mechanical properties of high-performance concrete reinforced with basalt fibre and polypropylene fibre. Construction and Building Materials 197:464-473. 
13. Ahmet B Kizilkanat, Nihat Kabay, VeyselAkyuncu et al. (2015) Mechanical properties and fracture behaviour of basalt ad glass fibre reinforced concrete: An experimental study. Construction and Building Materials 100:218-224.

14. Hao Zhou, Bin Jia, Hui Huang et al. (2020) Experimental Study on Basic Mechanical Properties of Basalt Fibber Reinforced Concrete. Materials 2020 13:1-20.

15. IS 1893 (Part 1): 2002, “Indian Standard Criteria for Earthquake Resistant Design Structures," Bureau of Indian Standards, Manak Bhavan, 9 Bahadur Shah Zafar Marg, New Delhi 110002.

16. Hao Zhou, Bin Jia and Hui Huang and Yanling Mou, 2020, Experimental Study of Basic Mechanical Properties of Basalt Fibber Reinforced Concrete, Materials 2020, Vol, 13, 1362

17. IS (Indian Standard) (1987) IS: 875 (Part 3) - 1987: Indian Standard Code of Practice for Design Loads (Other than Earthquake) for Buildings and Structures, Part 3: Wind Loads, Bureau of Indian Standards, Manak Bhavan, 9 Bahadur Shah Zafar Marg, New Delhi 110002.

18. IS (Indian Standard) (1987) IS: 875 (Part 1) - 1987, Indian Standard Code of Practice for Design Loads (Other than Earthquake) for Buildings and Structures, Part 1: Dead Loads, Unit Weights of Building Materials and Stored Materials, Bureau of Indian Standards, Manak Bhavan, 9 Bahadur Shah Zafar Marg, New Delhi 110002.

19. IS (Indian Standard) (1987) IS: 875 (Part 2) - 1987, Indian Standard Code of Practice for Design Loads (Other than Earthquake) for Buildings and Structures, Part 2: Imposed Loads, Bureau of Indian Standards, Manak Bhavan, 9 Bahadur Shah Zafar Marg, New Delhi 110002.

20. IS (Indian Standard) (1987) IS: 875 (Part 5) - 1987, Indian Standard Code of Practice for Design Loads (Other than Earthquake) For Buildings and Structures, Part 5: Special Loads and Combinations, Bureau of Indian Standards, Manak Bhavan, 9 Bahadur Shah Zafar Marg, New Delhi 110002.

21. IS (Indian Standard) (2000) IS 456: 2000, Indian Standard Plain and Reinforced Concrete Code of practice, Bureau of Indian Standards, Manak Bhavan, 9 Bahadur Shah Zafar Marg, New Delhi 110002

22. Issa, M. A., Ovitigala, T. and Ibrahim, M. (2016). Shear behaviour of basalt fibre reinforced concrete beams with and without basalt FRP stirrups. Journal of Composites for Construction, 20(4). 
